\section{Myeloperoxidase Deficiency: The Secret Under the Flag of Unstained Cell}

\author{
Myeloperoksidaz Eksikliği, \\ Boyanmamış Hücre Bayrağı \\ Altındaki Gizem
}

Türkan Patıroğlu 1 , Hatice Eke Güngör ${ }^{2}$, Julie Sawalle Belohradsky ${ }^{3}$, Ekrem Ünal ${ }^{1}$, Christoph Klein ${ }^{4}$

${ }^{1}$ Erciyes University, School of Medicine, Department of Pediatrics, Division of Pediatric Hematology and Oncology, Kayseri, Turkey

2 Erciyes University, School of Medicine, Department of Pediatrics, Division of Pediatric Allergy and Immunology, Kayseri, Turkey

${ }^{3}$ University Children's Hospital, Molecular Genetic Diagnostics, Infektionsimmunologisches Labor, Munich, Germany

${ }^{4}$ University Children's Hospital, Department of Pediatrics, Division of Pediatric Hematology and Oncology, Munich, Germany

Address for Correspondence: Hatice EKE GÜNGÖR, M.D.,

Erciyes University, School of Medicine, Department of Pediatrics, Division of Pediatric Allergy and Immunology, Kayseri, Turkey

Phone: +903524374901 E-mail: haticeekegungor@hotmail.com

Received/Geliş tarihi : January 22, 2012

Accepted/Kabul tarihi : March 29, 2012
Myeloperoxidase (MPO) deficiency is one of the most common inherited phagocyte defects, but it is rarely associated with clinical symptoms [1]. MPO, which is abundant in azurophilic granules of neutrophils and in the lysosomes of monocytes, plays a key role in amplifying the toxicity of hydrogen peroxide generated by the respiratory burst $[1,2]$. The diagnosis of MPO deficiency was rare before 1979; currently, the diagnosis is easily made due to the widespread use of automated flow cytochemical analysis in clinical hematology laboratories for enumerating peripheral blood neutrophils with peroxidase activity [2].

The MPO gene is encoded on chromosome 17q23 [3]. Primary deficiency of MPO is inherited as an autosomal recessive disorder. A secondary form of MPO deficiency has been described in various disorders, including lead poisoning, severe infections, neuronal lipofuscinosis, obstructive jaundice, diabetes mellitus, and such disseminated cancers as acute and chronic myeloid leukemia, myelodysplastic syndrome, and Hodgkin's lymphoma [1,2,4]. MPOdeficient neutrophils are markedly less efficient at killing Candida albicans and Aspergillus hyphae [1]. Although MPO is involved in killing certain microorganisms, to date, no particular susceptibility to persistent or severe infections has been noted in the vast majority of MPO-deficient patients $[1,2]$. Recurrent Candida infection has been observed predominantly in MPO-deficient patients that also have diabetes mellitus. In addition to infectious manifestations, the relationship between congenital MPO deficiency and the occurrence of malignancy remains controversial [1,2]. There is no specific treatment for MPO deficiency; however, in symptomatic patients antifungal treatment is crucial.

Herein we present a 17-year-old male that presented to our hematology department with neutropenia. Anamnesis showed that the patient did not have any recurrent or severe infection, but had been receiving benzathine penicillin prophylaxis due to acute rheumatic fever for years. Physical examination showed the following: weight: $58 \mathrm{~kg}$ (3-10p); height: $169 \mathrm{~cm}$ (10-25p); 1-2-degree/6 systolic murmur in the mesocardial region; the remainder of the examination was unremarkable.

Complete blood count results were as follows: hemoglobin: $13.1 \mathrm{~g} / \mathrm{dL}$; leucocyte count: 6140/ $\mathrm{mm}^{3}$; platelet count: $503,000 / \mathrm{mm}^{3}$. The formulation of the leucocytes was interesting, with an absolute neutrophil count of 20/ $\mathrm{mm}^{3}$ and a high absolute unstained cell count of $3020 / \mathrm{mm}^{3}$ (nearly 50\%). Although the absolute neutrophil count was 

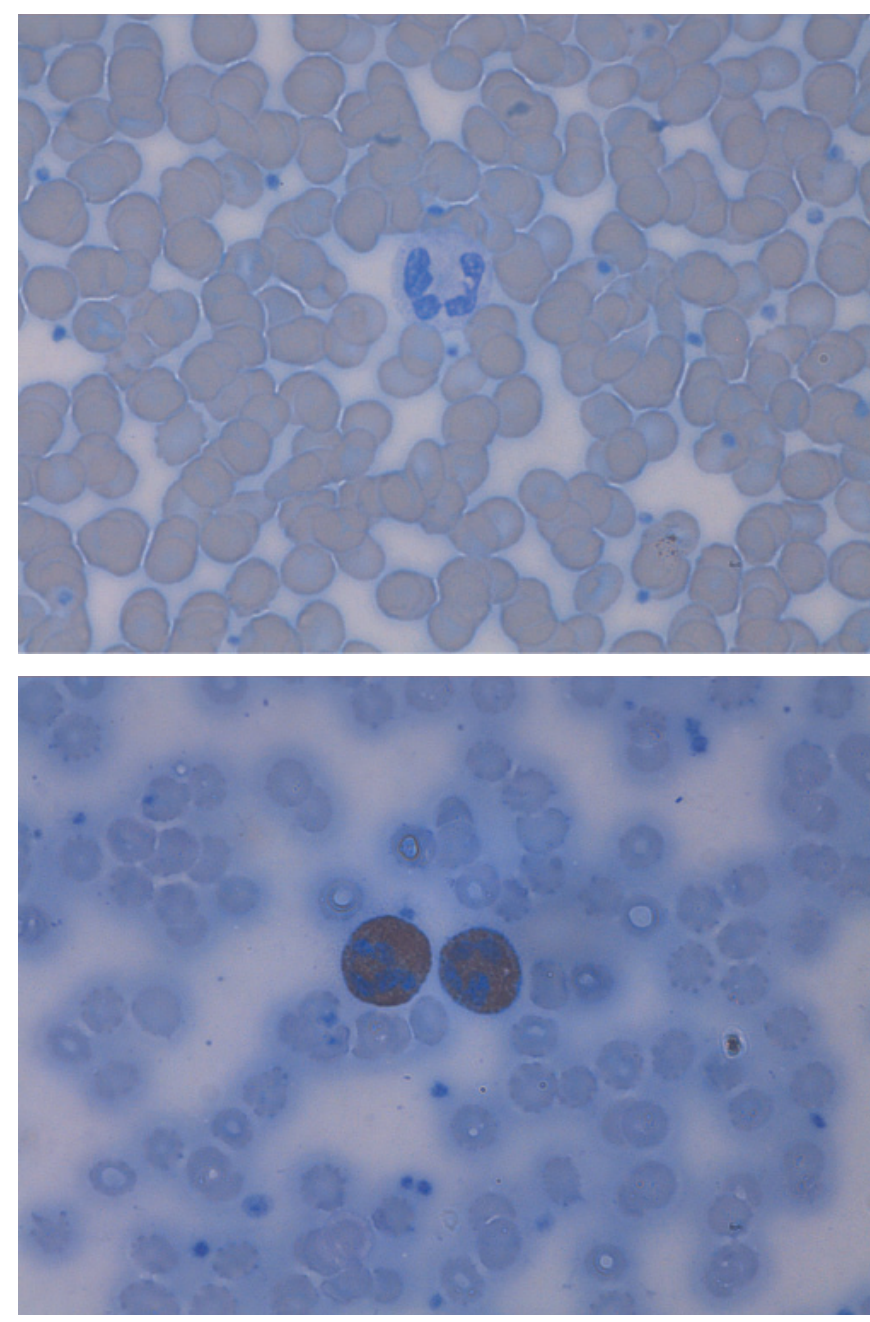

Figure 1: The cytochemical staining of the neutrophil from patient (a) shows negativity when compared to the control (b).

$20 / \mathrm{mm}^{3}$, peripheral blood smear showed normal formulation of leucocytes (49\% neutrophils, 47\% lymphocytes, and $4 \%$ monocytes). The inconsistency between the absolute

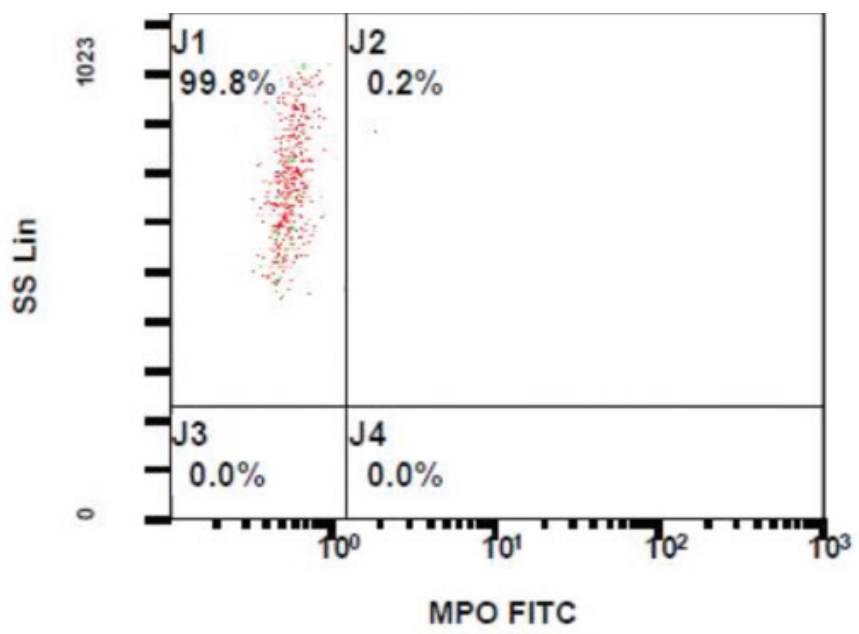

Figure 2: The flow cytometry analysis showed reduced positivity of myeloperoxidase at the gate of neutrophils. neutrophil count and the peripheral blood smear suggested the possibility of MPO deficiency, and we therefore performed cytochemical staining of peroxidase and flow cytometry analysis. Cytochemical staining of peroxidase was negative, as compared to the control (Figure la, lb), and flow cytometry analysis showed a dramatic decrease in $\mathrm{MPO}(+)$ neutrophils (Figure 2). In addition, we identified a compound heterozygous MPO gene mutation [c.1705C> T];[c.2031-2A>C]. The patient was followed-up for 12 months after his initial examination, during which time he was asymptomatic and healthy. In conclusion, we think that MPO deficiency must be considered in patients with incompatibility of neutropenia between smear and counter, especially when the flag of unstained cell is remarked.

Key words: Leucocyte function disorders, Myeloperoxidase, Neutrophil

\section{Conflict of interest statement}

The authors of this paper have no conflicts of interest, including specific financial interests, relationships, and/ or affiliations, relevant to the subject matter or materials included.

\section{References}

1. Dinauer MC, Newburger PE. The phagocyte system and disorders of granulopoiesis and granulocyte function. In: Orkin SH, Nathan DG, Ginsburg D, Look AT, Fisher DE, Lux SE, eds. Nathan and Oski's Hematology of Infancy and Childhood. 7th ed. Philadelphia: Saunders-Elsevier, 2009:1109-1221.

2. Lanza F. Clinical manifestation of myeloperoxidase deficiency. J Mol Med 1998;76:676-681.

3. Marchetti C, Patriarca P, Solero GP, Baralle FE, Romano M. Genetic characterization of myeloperoxidase deficiency in Italy. Hum Mutat 2004:23:496-505.

4. Arumugan G, Rajagopal R. Evaluation of neutrophil functions in obstructive jaundice patients. Turk J Hematol 2004:21:189-196. 